\title{
The Industry Development Mode Innovation of Wenzhou Foreign Trade E- Commerce
}

\author{
Lizhen Liu \\ Wenzhou Vocational and Technical College, Wenzhou 325035 \\ Xia441@sina.com
}

Keywords: Development model; Bottleneck; Industrial platform; Innovation

\begin{abstract}
The electronic commerce industry has characteristics of both information elements and modern commerce. It is an important point of strength while modern industry is transforming. "The Twelfth Five Year Plan" has made the electronic commerce industry as the national strategy. This paper introduced the advantages of electronic commerce; analyzed the current situation of Wenzhou outside of the electronic commerce; summarized the problems existing in reality; put forward some measures and strategy with electronic commerce; we hope to let Wenzhou electronic commerce development stand on a higher level.
\end{abstract}

\section{Introduction}

In the background of international financial crisis and the severe macroeconomic situation, electronic commerce industry of Wenzhou bucked the market trend In terms of quality and quantity. At present, the domestic big city has attached great importance to the development of electronic commerce industry. Many provinces look the electronic commerce industry as a pillar industry to develop. Wenzhou's e-commerce industry has a good foundation and the good momentum of development. How to further promote the development of Wenzhou is an important part of information industry while building Wisdom City, promoting industrial transformation and upgrading.

\section{The Advantages of Electronic Commerce}

Decrease International Trade Transaction Cost. First, compared with domestic trade, international trade document number range is more with high cost of treatment. Secondly, the buyer and the seller carry out business activities directly through the network avoiding middlemen participation, which can reduce the middle link of trade and reduce transaction costs. In addition, the use of electronic commerce to develop international trade can reduce inventory cost and save the storage fee.

To Improve Transaction Efficiency. First of all, the electronic commerce can optimize the organization within the enterprise, the management of customer information, inventory information, purchase information, sales information, payment information collation, recover the statistics, storage and so on by the computer to complete and can improve work efficiency. Secondly, internal information network and external network books in the enterprise, can accelerate the internal and external information exchange, so that information across the inner and outer space, achieve integration, so as to improve the management efficiency of decision making. Thirdly, to develop international trade with the electronic commerce, the seller and the buyer can use standardization, electronic contract, bill of lading, invoice, insurance certificate, bill, letter of credit, so that all relevant documents on the Internet can achieve instant delivery, greatly saving the transmission time of the documents, improving transaction efficiency significantly.

To Enhance National Competitiveness of Enterprises. Electronic commerce is the future development direction of international trade, which will become the mainstream. This encourages the user of electronic commerce markets. The foreign trade enterprises without the electronic commerce will lost a lot of business opportunities, while those who adopt electronic commerce enterprises will get more opportunities and enhance the competitiveness of enterprises. 


\section{Problems in Developing the Electronic Commerce}

The Development Bottleneck of Wenzhou Foreign Trade Business. In the process of rapid development of international e-commerce, there are also some problems. From the foreign trade ecommerce implementation process point of view, the main problem is the payment and settlement, tax issues and logistics problems. The foreign trade of electronic commerce involves long collection cycle. Some sellers cash flow stress, needing financial support. Logistics and almost all foreign trade business practitioners encountered a major problem, which mainly is the international high logistics cost. How to integrate resources is becoming the hot point of businesses.

Information Infrastructure is Weak. Network trade needs to achieve electronic data exchange in order to realize from the visit, negotiate, sign the contract goods to the automation of business process and in whole or in part of cash process, digital technology to use trade related organic connection between departments. But because of the economic strength, technology and other aspects, Chinese network infrastructure is still slow and backward, the low level of information, network congestion is slow and high tariffs and other factors is hindering the development of our electronic commerce. In view of limited hardware and software environment in the small and medium-sized enterprise the realization of e-commerce in international trade is very difficult.

The laws, Regulations in the International Trade Transactions with Network are not Sound. Transactions are in different legal systems. How to identify the authenticity of electronic commerce file information, how to regulate the electronic contract, e-commerce authentication, online transactions and online payment, intellectual property, electronic commerce and other electronic commerce all involve various legal issues of jurisdiction, which prevent an e-commerce application barrier. All these questions cannot be ignored.

\section{Wenzhou E-Commerce Industry Development Strategy}

The Strong Development Power Source Lies in the High Starting Point and Goal Orientation. Wenzhou is accelerating the wisdom city construction, innovation oriented city, which is one of the key to improve the level of information area and boost the development of the information industry. Therefore, to enhance the strategic positioning of e-commerce industry, the ecommerce industry will be a strategic pillar industry of Wenzhou.

To Speed up the Construction of E-Commerce Industrial Park. The first work is to build an innovative e-commerce enterprise gathering area. To learn from domestic and foreign well-known large-scale network and e-commerce enterprises, focusing on the introduction of B2B, B2C industry creating market headquarters enterprise clusters, and building a comprehensive industrial chain compound electronic commerce industry cluster. The second is the temperature information cooperation with Ningbo electronic commerce industry pioneer. Relying on the Ningbo and Wenzhou special docking advantage (transportation, logistics, industry, finance, and environment), the third is to build a model. From the development and operation mode of advanced base, establishing market docking, financial incubator, brand promotion, technology development, personnel training as the main characteristics of the service system, and establishing the park industry public service platform. The forth is the regional electronic commerce market center. The most important is to establish electronic commerce products and logistics supporting center and to accelerate traditional industry information and e-commerce to upgrade.

\section{Innovation of Foreign Trade E-Commerce Model}

To Establish and Improve Wenzhou Industry Development Policy System of E-Commerce. First, to promote the electronic commerce development. We must establish e-commerce Industrial Park, and build up electronic commerce public technology service platform and public information service platform and electronic business incubators. Second, with fiscal support policies, we should 
establish special funds for the development of electronic commerce industry. Third we must improve the foreign trade e-commerce venture financial environment to explore the establishment of network bank risk pool, to establish venture capital fund of venture capital financing platform allowing the third party e-commerce advantages of the service enterprise. Forth, we need to support the introduction of talent and development. At the same time, we need to strengthen cooperation with domestic famous universities, to train applied talents with high level.

Innovation about Trading Program Transformation. To make changes to the traditional ideas of enterprises, relevant departments need to actively guide the enterprises engaged in foreign trade ecommerce, let more enterprises understand the broad prospects for development of electronic commerce in foreign trade. Related enterprises in Wenzhou need to change the idea, to adapt to the new situation of trade. Electronic commerce can achieve fine sales and management. The traditional enterprises sometimes charge a deposit but not timely delivery, so the seller of electronic commerce in foreign trade will be caused by the adverse effects. Therefore, the stable high quality electric supplier group is of great significance.

The Mechanism Reform. In one aspect, we need to establish a leading group for the development of electronic commerce industry led by City Hall, and set up an office, as a permanent office.

The other aspect is to build the Wenzhou City Association of e-commerce led by the leading group office as the electronic commerce industry exchange platform. The third is to build the ecommerce Industrial Park as the introduction of major projects by the zone project preparation, formulation personalization policies, and to report to the leadership group meeting to consider the adoption of the implementation.

Innovation of the Trade Transportation in Electronic Management. We should establish transport NET in the major ports in the world to realize the cargo booking, document transfer, container management, shipping management, cargo tracking and management with the international standard EDI documents, and accelerate trade circulation, promote foreign trade enterprise scale management and specialization, modern management, improving the ability to compete in international market.

Electronic Payment Innovation of the International Trade. Payment is the realization of electronic payment in the network. It is the funds deposited in the electronic bank or credit company computer after a transaction is concluded. If we input credit card number in the network terminal, the fund can be used as transfer, credit services, and a high-speed operation of the bridge between customers and banks, bank with the bank will be built.

Innovation of International Trade Regulation. Invisible, the network will serve for e-commerce transactions to innovate governments on the international trade regulation, especially in the areas of tariffs, customs, and import and export inspection as soon as possible to adapt to the needs of the development of electronic commerce.

Innovation of the Key Technology Research Methods. Technical problems of electronic commerce development are the common problem every country faces. Due to the relatively weak technology research efforts, to solve this problem is particularly urgent. Through the development of electronic commerce in international trade, involving banks, foreign trade and its related business tax, customs, foreign exchange, insurance and other departments and the industry, coordination and joint efforts of the electronic commerce in our country implementation also will depend on the efforts on the above sectors, departments and units. Research must focus on security technology, security management, CA certification and electronic payment and other key technologies. In order to early realize the domestic network, we must work hard to establish a national foreign trade private information network with the United Nations trade information network and other international business information network in a relatively short period of time to make our city technical research have an obvious improvement.

Transformation of Training the Mode of E-Commerce Talent. Electronic commerce demands for high quality employees. They Not only need to be familiar with the knowledge of computer network information technology, but also need to grasp the international economic trade related theory knowledge, also need to know the regulations and requirements of trade links and the countermeasures. The government should invest more in research and application of electronic 
commerce in terms of investment, establish and perfect the operation mechanism of electronic commerce and train a number of electronic commerce technology, legal aspects of R \& D personnel and management personnel. Foreign trade e-commerce itself needs professional management and planning talents. Operation process is also required for international trade and the Internet combined with foreign business activities to provide professional services. Therefore, to develop this industry we need to train professional talents with many aspects of business quality, both familiar with relevant laws and regulations, but also mastering the foreign language, proficient in international trade and business knowledge, professional skills and the internet.

\section{Conclusions}

Foreign trade e-commerce will shorten the chain distance between producers and consumers of supply change the traditional market structure. On the one hand it will supply foreign trade enterprises more opportunities, change the traditional marketing mode. On the other hand, it shortens the chain distance between the manufacturer and the customer, reduce intermediate links, and reduce management cost. With the help of electronic business and the changed market structure, the business has changed greatly. China's foreign trade enterprises have improved in not only the change in marketing mode, operating costs, but also the original traditional store business. With the help of the international electronic commerce city construction, the traditional industrial park and electronic commerce, foreign trade and other characteristics of effective integration, Electronic Commerce industry Park can give vitality to the small and scattered e-commerce business subject to enter the park and form the resultant force of development, to make Wenzhou an e-commerce trade base advance fast and best.

\section{Reference}

[1] Wang Jianfeng. Investigations of the Electronic Commerce Restricting Factors of Enterprise [J]. Electronic Commerce, 2010 (1)

[2] Huang Na, Luo Bingxin. The Thinking of China's Small and Medium-sized Enterprise with the Electronic Commerce Application [J]. Heihe Journal, 2010 (4)

[3] Joe pingping. [J]. Analysis of the Impact of E-commerce on International Trade, 2011 (10)

[4] Zhou Lan. Relationship Research between International Trade and Electronic Commerce [J]. Material Flow Management, 2012 (2)

[5] Zhao Meitian. The Electronic Commerce Strategy of the Small and Medium-sized Foreign Trade Enterprises [M].2008-10-27 